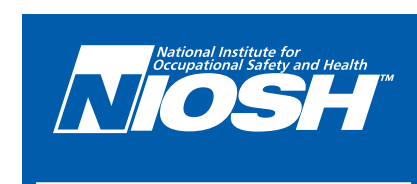

ENGINEERING INTERVENTIONS
Reducing Winch Entanglements With Stationary Guarding

Commercial Fishing Safety Research and Design Program

\title{
BACKGROUND
}

The US Coast Guard approached NIOSH about an increase in the number of winch entanglement injuries being reported among commercial shrimp fishermen in the Gulf of Mexico. In August of 2012, a 15 year-old boy, fishing on a shrimp boat, died when his clothing became caught in an operating deck winch. This fatality received widespread coverage within the industry and further highlighted the need for action.

Using the NIOSH Commercial Fishing Incident Database (CFID), researchers at the Alaska Pacific Office began studying the incidence of shrimp winch entanglements and found a total of 35 severe work-related injuries, including eight fatal injuries, caused by deck winches reported in the Southern shrimp fleet from 2000-2011.

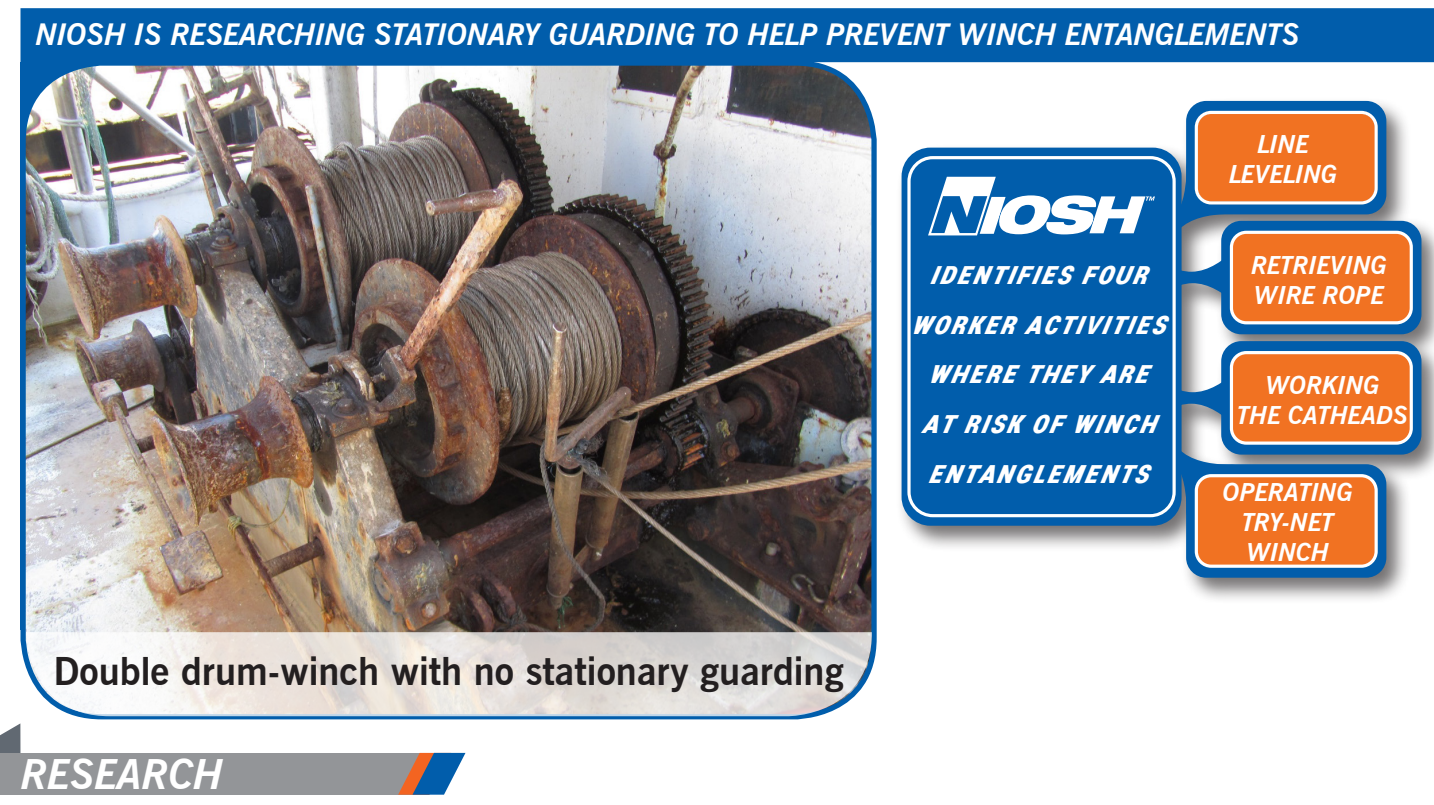

In the fall of 2013, a NIOSH contractor conducted dock side surveys to identify three of the most common drum winches used on Gulf of Mexico side-trawl shrimp vessels. The survey identified particular main-winches for guarding: the McElroy/Catchot 505, and 503 and the Stroudsburg $5151 / 2 \mathrm{~T}$ winches. NIOSH engineers designed standardized stationary guarding for each identified main-winch and built initial prototype guards for each model to be sea-tested.

NIOSH formed partnerships with boat owners to test the guard designs on each type of winch. The Gulf of Mexico shrimp fleet is diverse, both geographically and culturally. NIOSH sought to find boat owners from the various cultural groups to collaborate with the winch-guard testing. Three working side-trawl shrimp boats were chosen as test vessels operating out of Dulac, LA, Port Arthur, TX and Chauvin, LA. 


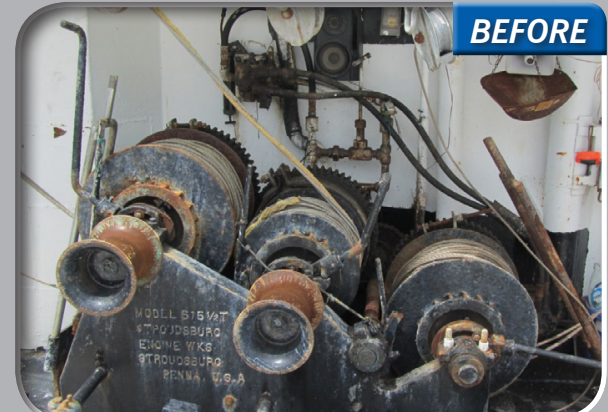

515 1/2 T Stroudsburg triple-drum winch without stationary guard

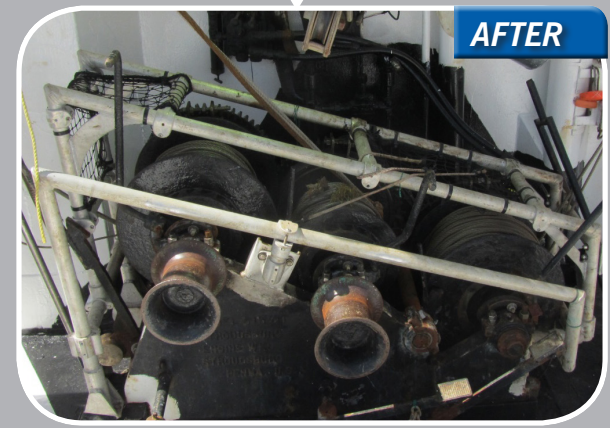

515 1/2 T Stroudsburg triple-drum winch with prototype guard installed

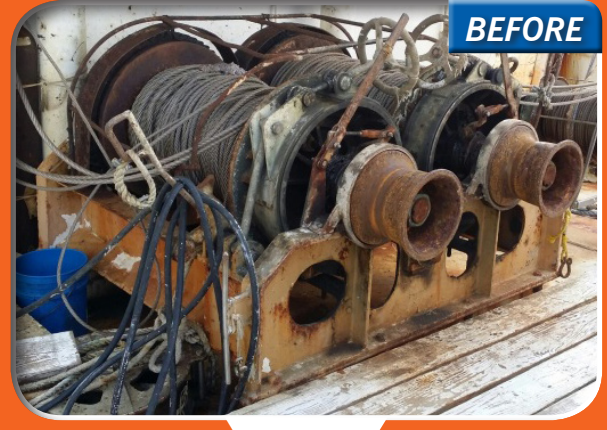

505 McElroy double-drum winch with minimal stationary guard

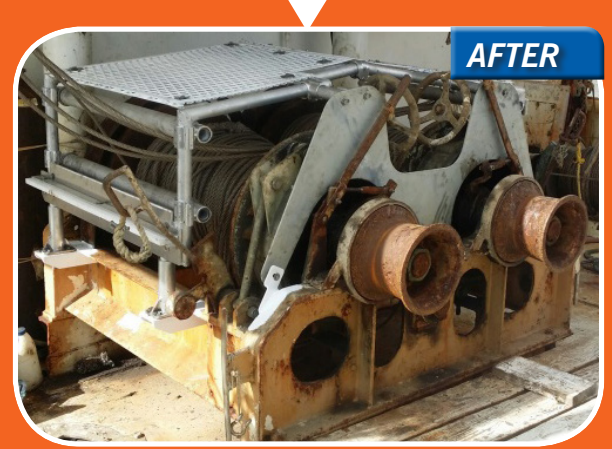

505 McElroy double-drum winch with prototype guard installed

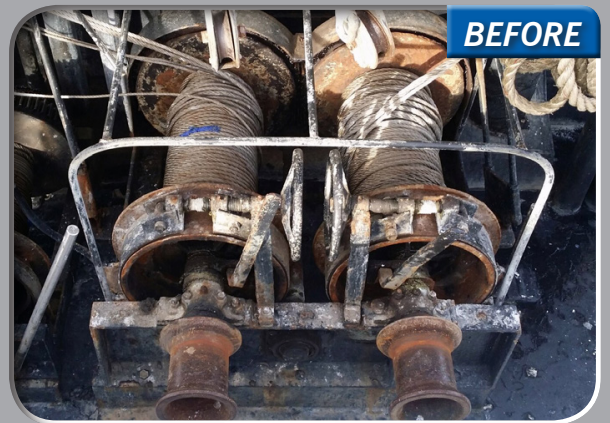

503 McElroy double-drum winch with minimal stationary guard

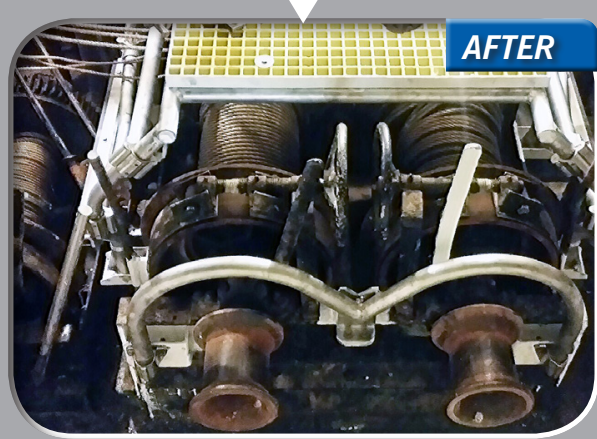

503 McElroy double-drum winch with prototype guard installed

\section{ONGOING OUTPUTS}

NIOSH has completed initial designs for stationary-winch guards for three of the most commonly used models of winches currently used by the Gulf of Mexico shrimp fleet. Through collaborations and partnerships with shrimper associations and safety groups, the successfully tested winch guard design plans will also be made available to shrimpers via various internet websites. NIOSH intends to release the information in English, Spanish, and Vietnamese to better reach the target audience. The refined designs, including material specifications and estimated building costs, are scheduled to be available without charge to fishermen.

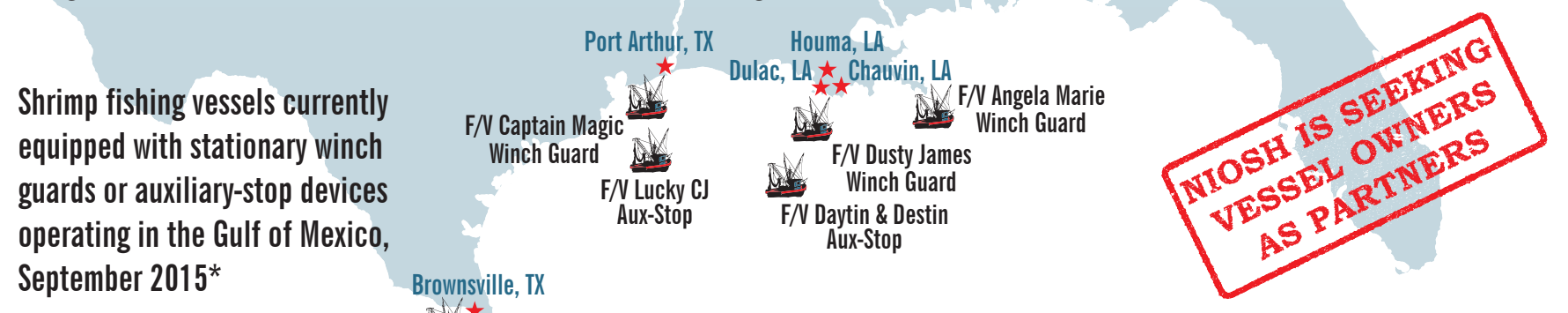

$$
\begin{gathered}
\star \\
\text { Aux-Stop }
\end{gathered}
$$

Mention of any company or product does not constitute endorsement by the National Institute for Occupational Safety and Health (NIOSH).

'Centers for Disease Control and Prevention. Fatal and Nonfatal Injuries Involving Fishing Vessel Winches Southern Shrimp Fleet, United States, 2000-201 I. MMWR 2013;62:157-160.

*You can find more information about other NIOSH engineering interventions by visiting www.cdc.gov/ niosh/topics/fishing/engineering or follow us on Twitter @NIOSHFishing

U.S. Department of Health and Human Services

Centers for Disease Control and Prevention

National Institute for Occupational Safety and Health

To receive NIOSH documents or more information about occupational safety and health topics, please contact NIOSH. Telephone: I-800-cdc-info (I-800-232-4636) |TTY: I-888-232-6348 | www.cdc.gov/info. For a monthly update on news at NIOSH, subscribe to NIOSH eNews by visiting www.cdc.gov/niosh/eNews. DHHS (NIOSH) Publication No. 20I6-I04. December, 2015.
If you are interested in learning more about NIOSH's work in the Gulf of Mexico, or if you want to become a partner in the research or dissemination efforts, please contact:

Mr. Chelsea Woodward

Commercial Fishing Safety Research and Design Program CDC, NIOSH, Western States Division

Spokane Research Laboratory

509-354-8073 or ciw1@cdc.gov. 